$$
\text { http://dx.doi.org/10.12819/2021.18.02.1 }
$$

\title{
Qualidade de Vida no Trabalho e Suporte no Trabalho Terceirizado de Organizações de Crédito
}

\author{
Quality of Life at Work and Support in Work of Credit Organizations
}

Fernando Thiago

Doutor em Administração pela Universidade Municipal de São Caetano do Sul Professor da Universidade Federal de Mato Grosso do Sul

E-mail: fernando.t@ufms.br

Thais Caroline Cruz Araújo

Graduada em Administração pela Universidade Federal de Mato Grosso do Sul

E-mail: carolinethais597@gmail.com

Caroline Gonçalves

Pós-doutora em Economia pela Universidade de São Paulo - FEA/USP

Doutora em Administração pela Universidade de São Paulo - FEA/USP

Professora da Universidade Federal de Mato Grosso do Sul

E-mail: goncalves.caroline@ufms.br

Wilson Ravelli Elizeu Maciel

Doutor em Administração pela Universidade Federal de Mato Grosso do Sul Professor da Universidade Federal de Mato Grosso do Sul

E-mail: wilson.ravelli@ufms.br

Endereço: Fernando Thiago

Universidade Federal de Mato Grosso do Sul - Campus do Pantanal - Avenida Rio Branco, 1.270 - Bairro Universitário - Corumbá/MS - 79304-902. Brasil.

Endereço: Thais Caroline Cruz Araújo

Universidade Federal de Mato Grosso do Sul - Campus do Pantanal - Avenida Rio Branco, 1.270 - Bairro Universitário - Corumbá/MS - 79304-902. Brasil.

Endereço: Caroline Gonçalves

Universidade Federal de Mato Grosso do Sul - Campus do Pantanal - Avenida Rio Branco, 1.270 - Bairro Universitário - Corumbá/MS - 79304-902. Brasil.

Endereço: Wilson Ravelli Elizeu Maciel

Universidade Federal de Mato Grosso do Sul - Campus do Pantanal - Avenida Rio Branco, 1.270 - Bairro Universitário - Corumbá/MS - 79304-902. Brasil.
Editor-Chefe: Dr. Tonny Kerley de Alencar Rodrigues

Artigo recebido em 02/12/2020. Última versão recebida em 06/01/2021. Aprovado em 07/01/2021.

Avaliado pelo sistema Triple Review: a) Desk Review pelo Editor-Chefe; e b) Double Blind Review (avaliação cega por dois avaliadores da área).

Revisão: Gramatical, Normativa e de Formatação 


\title{
RESUMO
}

Este artigo teve como objetivo verificar a relação entre qualidade de vida no trabalho e suporte no trabalho em organizações de crédito. A metodologia empregada foi a quantitativa, descritiva, utilizando a técnica de levantamento (survey) aplicado a uma amostra de operadores de negócios de crédito terceirizados em correspondentes bancários de CorumbáMS. Os dados foram coletados por meio instrumento de avaliação de qualidade de vida no trabalho (IQVT) baseado no modelo de Walton (1973) e validados por Timossi et al. (2009) e pela Escala de Percepção de Suporte Organizacional (EPSO) validada por Siqueira e Gomide Jr. (2008). Os resultados apresentaram que os colaboradores de correspondentes bancários terceirizados apresentam níveis neutros a satisfatórios em termos de qualidade de vida e neutros a insatisfatórios no trabalho e suporte no trabalho. $\mathrm{O}$ teste de correlação apresentou uma correlação positiva de $75 \%$ entre os construtos observados, com significância de 0,001 .

Palavras-chave: Qualidade de Vida no Trabalho. Suporte no Trabalho. Organizações de Crédito. Terceirização.

\begin{abstract}
This article aimed to verify the relationship between quality of life at work and support at work in credit organizations. The methodology used was quantitative, descriptive, using the survey technique applied to a sample of credit business operators outsourced to bank correspondents in Corumbá-MS. Data were collected using an instrument for assessing quality of life at work (IQVT) based on Walton's model (1973) and validated by Timossi et al. (2009) and the Organizational Support Perception Scale (EPSO) validated by Siqueira and Gomide Jr. (2008). The results showed that the employees of outsourced banking correspondents present neutral to satisfactory levels in terms of quality of life and neutral to unsatisfactory at work and support at work. The correlation test showed a positive correlation of $75 \%$ between the constructs observed, with a significance of 0.001 .
\end{abstract}

Keywords: Quality of Life at Work. Support at Work. Credit Organizations. Outsourcing. 


\section{INTRODUÇÃO}

A satisfação e qualidade de vida do trabalhador em suas atividades têm sido objetivos a serem alcançados pelas corporações ao longo dos anos, com vistas à melhoraria dos indicadores de comprometimento, produtividade e saúde dos trabalhadores, contribuindo com os resultados organizacionais.

A qualidade de vida no trabalho possui dois aspectos. $\mathrm{O}$ primeiro surge de uma demanda dos trabalhadores por melhores condições laborais (ALVES; CORREIA; SILVA, 2019), o segundo é uma busca das empresas para que se tenha o aumento da produtividade (CARNEIRO; LÉDO, 2019).

Esse processo de melhoria contínua do trabalho passa pelo comprometimento das organizações em atender as reivindicações dos colaboradores, como nos aspectos apontados por Vasconcelos (2001): compensação justa e adequada, condições de trabalho, uso e desenvolvimento de capacidades, oportunidade de crescimento e segurança, integração social e organização, constitucionalismo e trabalho e espaço total de vida. Todos esses critérios dependem do engajamento da organização para aperfeiçoar ou modificar processos e até sua cultura organizacional.

Após a promulgação da Lei Federal n. 13.429 de 2017 que trata das atividades que podem ser terceirizadas, foi eliminada a divisão entre as atividades meio, como segurança e limpeza, das atividades fim, que trata da produção ou prestação dos serviços aos clientes finais. A partir desse momento rompem-se as barreiras que limitavam a terceirização e se abre um leque de possibilidades para as empresas readequarem quadros funcionais, reduzirem custos e se desvincularem de responsabilidade trabalhistas.

Se para a empresa a lei da terceirização se mostrou benéfica para o empregador, para os funcionários se mostrou um risco à perda dos fatores que geram qualidade e satisfação em seu trabalho. Porém, a terceirização não pode significar redução da qualidade de vida do trabalhador, sem o suporte da organização para este aspecto, a produtividade laboral cai e criam-se diversos problemas organizacionais diante da insatisfação coletiva.

Em instituições financeiras esse serviço de terceirização está enraizado nas atividades por meio dos correspondentes bancários, empresas que realizam negócios do setor de crédito com clientes dos bancos e em troca recebem uma comissão. Para os bancos, representam uma oportunidade de prospectar mais negócios, reduzir seu quadro funcional, compromissos trabalhistas, descentralização de atividades e dinamização de seus negócios via empresas especializadas. 
Essa pesquisa se justifica por observar a qualidade de vida e o suporte no trabalho destes prestadores de serviços terceirizados, especificamente os que atuam na atividade fim de uma empresa, pois estes trabalhadores contratados não possuem os mesmos vínculos e direitos legais dos funcionários efetivos da empresa. Na prática, é justificável a relevância deste trabalho para análise desse setor que está em expansão no Brasil. Além disso, permite verificar a relação entre suporte no trabalho e qualidade de vida no trabalho, contribuindo para a teoria da área.

O problema central deste artigo é: Qual a relação entre o suporte no trabalho dado por suas empresas (terceirizadas) e qualidade de vida no trabalho de operadores de crédito?

Para tanto, o objetivo do artigo foi verificar a influência do suporte no trabalho na qualidade de vida de um grupo de trabalhadores em correspondentes bancários de CorumbáMS.

\section{REFERENCIAL TEÓRICO}

\subsection{Qualidade de vida no trabalho}

As pesquisas acerca da Qualidade de Vida no Trabalho (QVT) não são recentes. Segundo Reis (2003), ao final do século XVIII, quando se iniciou a Revolução Industrial, o novo modelo de organização do trabalho modificou a sociedade, no qual os artesãos e camponeses passaram a ser operários, e as indústrias, na busca de maior produtividade e lucro, passaram a impor uma alta exigência sobre estes operários.

A partir da consolidação do movimento da Revolução Industrial, alguns levantes sociais surgiram, exigindo o rápido e melhorado atendimento às reivindicações trabalhistas (por melhora nas condições e menores jornadas, com remunerações mais satisfatórias), sendo neste período o pensamento em QVT aplicado apenas quando ocorriam os acidentes de trabalho (GRÜNSPAN, 2005; SILVA; TARANTO; PIASECKI, 2006).

Na referida época, a preocupação dos estudiosos estava centrada na organização do trabalho, em função do advento da Administração Científica, representada principalmente por Frederick Wislow Taylor. A aplicação de seus pressupostos causou mudanças que melhoraram o modelo de remuneração dos funcionários. No entanto, deu-se início aos trabalhos repetitivos e sincrônicos, em função da visão dos trabalhadores como máquinas e que tinham como o elemento motivador, o salário (ALVAREZ, 2002). Porém, com o passar do tempo, as organizações passaram a demonstrar preocupação com a satisfação do 
trabalhador na realização de suas atividades, com a finalidade de aumento dos índices de produtividade dos trabalhadores (FERNANDES, 1996).

A qualidade de vida no trabalho (QVT), como aponta Timossi et al. (2009), é um conceito que trata de uma questão de saúde física e psicológica, na qual sua percepção pode ser subjetiva e o empregador é reativo a afetos negativos e positivos. A partir disto, pode-se criar juízo de valor sobre sua qualidade de vida no trabalho e, também, a psicológica, em que aspectos emocionais como o propósito de vida, realização, sociais, crescimento profissional, ambiente e autonomia são levados em conta no grau de satisfação com o QVT.

As duas correntes, subjetiva e psicológica, são distintas na forma de análise, porém podem ser complementares quando analisadas com enfoque na atividade do trabalhador dentro da empresa e com menor intensidade sobre sua vida fora da empresa (DESSEN; PAZ, 2010).

Há um conceito mais recente incorporado na satisfação do trabalho que é o conceito de qualidade de vida no trabalho, que engloba além da satisfação do trabalho, o envolvimento com o trabalho e comprometimento organizacional (TIMOSSI et al., 2009).

O conceito de QVT pode ser compreendido como o somatório das práticas de uma organização para a implementação de avanços e inovações tecnológicas no ambiente organizacional (VASCONCELOS, 2001). O QVT quando bem trabalhado nas organizações, pode propiciar hábitos saudáveis nos ambientes organizacionais e, como consequência, melhoria na condição de vida dos trabalhadores e maior comprometimento organizacional (LÍRIO; SEVERO; GUIMARÃES, 2018).

Complementando este conceito, Milhome, Rowe e Santos (2018) explicam que a QVT é formada por fatores que atuam nas aspectos físicos, psicológicos, sociais, de saúde e recompensas que, em conjunto, promovem o bem-estar dos colaboradores, impactando não apenas no desempenho organizacional, mas também na imagem da empresa.

Hammer e Zimmerman (2011) apontam as alterações no mercado de trabalho e na forma do trabalho em si, ocorridas nos últimos anos, que trouxeram um novo horizonte para o estudo da QVT e, consequentemente, o aumento do estudo deste: o envelhecimento da população, maior participação das mulheres no mercado de trabalho, a quantidade de horas trabalhadas, a flexibilidade dos turnos de trabalho, além das alterações nos locais de trabalho.

As políticas de QVT adotadas carecem de uma aproximação da realidade organizacional e não apenas uma política genérica para que satisfaça a legislação, sendo escrita apenas de forma demagógica (DESSEN; PAZ, 2010). 
Neste sentido, as empresas estão empenhadas em utilizar o QVT como ferramenta de gestão das práticas de satisfação no trabalho, para diminuir o atual distanciamento entre o discurso de valorização do trabalhador e a prática realizada com seus colaboradores (VASCONCELOS, 2001).

A teoria da QVT foi iniciada nos anos 1970 abordada como uma variável da reação do indivíduo ao trabalho e como forma de melhorar sua condição. Posteriormente surgiu a abordagem com foco no indivíduo antes da organização, que se aprimorou ao tentar elaborar métodos psicológicos e sociais para avaliação da satisfação. É um conceito que passa pela avaliação continua da qualidade de vida do trabalhador em vários aspectos sociais e científicos (LÍRIO, 2018).

Neste novo conceito no qual as dimensões do QVT abrangem diversas áreas do conhecimento, admite-se que elas tendem a contribuir para a análise da satisfação no trabalho (VASCONCELOS, 2010). Além disso, atua em conjunto com outras áreas: saúde, que busca contribuir com a saúde mental, física e psicológica; ecologia: que leva em conta a preservação da natureza e meio ambiente; ergonomia: leva em conta o conforto no trabalho e a medicina no trabalho; psicologia: compõe-se com a filosofia, trata de individualidade de cada pessoa no seu trabalho e suas necessidades individuais; sociologia: aplica os contextos culturais e antropológicos dos indivíduos e da sociedade; economia: trabalha com o conceito econômico de que o trabalho é um fator de produção e de que os recursos são escassos e devem ser bem alocados; administração: gestão para concentrar os recursos e alcançar os resultados almejados; e engenharia: trabalha os métodos de aplicação dos recursos em sua plenitude.

Ao longo do tempo a ideia de que as evoluções tecnológicas trariam aos trabalhadores maior comodidade em sua atividade profissional, com menos tempo trabalhado e melhor qualidade foi revista, uma vez que os trabalhadores ainda adoecem em função do serviço e continuam com pouco tempo para lazer em relação ao tempo demandado para o trabalho.

O Anuário do Sistema Público de Emprego, Trabalho e Renda 2016, que apresenta indicadores da saúde do trabalhador, com base na RAIS publicado pelo Dieese (2017), mostrou que doenças do trabalho, como Lesão por esforço repetido (LER) e depressão cresceram 25\% em dez anos no Brasil, no período de 2005 a 2015. Para efeito de comparação, considerando todos os tipos de acidente no trabalho, o aumento foi de $10 \%$. Isso demonstra crescimento acima da média dos acidentes de trabalho causados por doenças de causa profissional ou do trabalho. Em 2014, conforme dados da pesquisa do Dieese (2017), 704.136 pessoas por ano sofrem algum tipo de acidente ou adoecem no trabalho. 
Uma explicação para este aspecto nefasto da realidade laboral do país é que, conforme aponta Handy (1995), o mercado de trabalho deixou de ser uma troca da mão de obra que se traduz pela sua capacidade de produzir bens e serviços e passou para um comércio do tempo dos trabalhadores. Hoje se leva em conta o tempo que um trabalhador passa dentro de uma empresa, na qual se adquire o direito sobre esse tempo.

Com isso as pessoas acabam abdicando de mais horas de lazer e substituindo-as por horas de trabalho, pois as necessidades sociais são crescentes, somadas a desejos ilimitados. Este fato leva as pessoas a ultrapassarem a curva de "desutilidade marginal" do trabalho, em que as horas trabalhadas são muito superiores às horas destinadas ao lazer, o que leva a um desequilíbrio do mercado de trabalho, com pessoas trabalhando mais por salários menores (KEYNES, 2014).

Isso leva a compreender que as pessoas passam cada vez mais tempo nas organizações e que este é um movimento muito difícil de ser revertido. O que se pode fazer a respeito é que, se os trabalhadores passam significativa parcela do tempo no ambiente de trabalho, é fundamental que ele se sinta bem em seu local de serviço (DESSEN; PAZ, 2010).

Quanto mais tempo as pessoas passam no trabalho no mundo moderno, mais as empresas buscam compreender as relações de satisfação do trabalho, avaliação dessa satisfação e as políticas de melhoria nas condições de trabalho, como forma de também aumentar sua produtividade.

Para analisar o nível de satisfação no trabalho, Walton (1973) apresenta categorias conceituais de QVT para um modelo de avaliação, por meio de fatores a serem levados em conta pela QVT e suas dimensões:

1. Compensação justa e adequada: corresponde ao pagamento de salário ao serviço prestado, além da distribuição dos lucros em ganhos de produtividade. Por fim, a igualdade dos salários internos para cargos equivalentes e para funcionários de outras empresas equivalentes.

2. Condições de trabalho: trata do trade-off entre lazer e trabalho, com uma jornada de trabalho justa que contemple horas de lazer. Somado a isto um ambiente de trabalho saudável e sem insalubridade.

3. Uso e desenvolvimento de capacidades: sobre aproveitar a capacidade intelectual, dando autonomia e permitindo autocontrole ao funcionário para que ele utilize seu potencial, também dar constantes retornos sobre o resultado do serviço prestado (feedback). 
4. Oportunidade de crescimento e segurança: aborda a política de carreira e valorização do funcionário pela organização. Aborda o encarreiramento, o crescimento pessoal, os ganhos salariais e segurança no trabalho.

5. Integração social da organização: um dos temas mais atuais e relevantes, sobre a igualdade de oportunidades entre os colaboradores sem distinções preconceituosas de cor, raça, gênero, mobilidade e relacionamento com superiores.

6. Constitucionalismo: refere-se ao respeito das leis trabalhistas, também da privacidade pessoal, liberdade de expressão e imparcialidade.

7. Trabalho e espaço total de vida: ressalta a carga horária de trabalho que seja razoável, além da estabilidade nos horários no local de trabalho e tempo para lazer.

8. Relevância social do trabalho: o espírito de pertencimento do funcionário à empresa. O quanto ele se vê representado pela organização. Questões como responsabilidade social, responsabilidade dos produtos, imagem pública de empresa e políticas de emprego são levadas em conta.

Esses conceitos corroboram a ideia de multidisciplinaridade que o conceito de QVT moderno aborda. Vasconcelos (2001) aponta que seja razoável sintetizar os temas abordados de acordo com a área de atividade desenvolvida, analisando de duas formas, intrínseca, sobre a tarefa que está sendo realizada e sua forma de execução e extrínseca, sobre o contexto da atividade, e tudo que está envolvido no entorno do trabalho.

O modelo de Walton (1973) é passível de ser adaptado a diversos tipos de atividade, pela sua abrangência e por se utilizar de diversas ciências para análise. Borges, Valle e Fabricio (2015) argumentam que além de o autor ser o pioneiro na pesquisa de modelos de análise de QVT, seu modelo permite a aplicação de experimentos de verificação de satisfação no trabalho importantes para melhoria da qualidade de vida, dentre seus oito itens de avaliação.

A próxima seção trata do suporte no trabalho oferecido pelas organizações que possui relação direta com os resultados organizacionais conforme será apresentado.

\subsection{Suporte no trabalho}

Para que seja possível uma adequada qualidade de vida no trabalho, faz-se necessário que a empresa atue como um sustentáculo ao colaborador. No conceito de suporte no trabalho para Cobb (1976), entende-se o suporte social como a informação que leva o indivíduo a 
acreditar que é amado e que os outros se preocupam, que é apreciado e que pertence a uma rede de relações de obrigações mútuas.

Outra análise do tema, a de House (1981), considera que o suporte social compreende um conjunto de comportamentos de suporte vistos como potenciais formas de suporte social, tais como: suporte emocional (empatia, carinho, confiança, estima, preocupação e escuta atenta do outro), suporte instrumental (ajuda direta em termos financeiros, de tempo ou trabalho), suporte informacional (sugestões, conselhos e toda e qualquer informação útil na resolução de problemas pessoais ou de trabalho) e suporte avaliativo (informação relevante a autoavaliação e feedback de outros, útil na autoafirmação) que pode ser incluído no suporte informacional. Sendo assim, o autor considera o suporte emocional mais importante que o suporte social. No trabalho, o suporte prestado pelos supervisores seria o elemento mais importante, seguido do suporte prestado pelos colegas de trabalho.

Siqueira e Padovan (2008) destacam que passa pela decisão de um gestor, o apoio aos colaboradores em termos dos fatores relacionados ao suporte no trabalho que, neste aspecto, possibilita melhorias na satisfação no trabalho. A falta de informação sobre os pontos a serem melhorados torna-se um dos principais empecilhos para uma política efetiva da empresa.

Diante dos temas abordados, é possível que exista uma correlação entre qualidade de vida no trabalho e suporte organizacional, uma vez que, tendo a organização oferecido este apoio ao trabalhador, isto pode refletir em melhor qualidade de vida no trabalho, o que torna possível a elaboração da hipótese de pesquisa:

H1. Correlação positiva entre Qualidade de Vida no Trabalho e Suporte no Trabalho de funcionários terceirizados de operadoras de créditos.

Como forma de testar a hipótese, o próximo capítulo versará sobre os procedimentos metodológicos aplicados nesta pesquisa.

\section{METODOLOGIA}

O método utilizado foi o quantitativo com a aplicação de questionário aos trabalhadores do setor de correspondente bancário na cidade de Corumbá, MS, com vistas a obter dados sobre suporte no trabalho e qualidade de vida no trabalho deste grupo social.

A abordagem quantitativa tem por objetivo estabelecer coerência na pesquisa científica por meio de uma correlação entre arcabouço teórico utilizado com os dados empíricos coletados. Este aspecto permite evitar as possibilidades de distorções da realidade e 
interpretações equivocadas, uma vez que dados coletados com procedimentos adequados se tornam importantes fontes de conhecimento sobre a realidade (OLIVEIRA, 1997).

Dalfovo, Lana e Silveira (2008) definem métodos quantitativos como qualquer objeto de pesquisa que seja possível quantificar por meio de números, ser categorizado e observado teoricamente, como uma pesquisa aqui apresentada, com a percepção dos funcionários quantificada pelas respostas no formulário e analisada à luz das teorias de QVT e Suporte no Trabalho.

Quanto aos objetivos, a pesquisa se caracteriza como descritiva. Gil (2019) esclarece que esta classe de pesquisa busca explanar atributos do fenômeno a ser estudado, dar sentido ao fenômeno, relacionar a causa e efeito entre as variáveis em questão, conceder uma visão detalhada do problema objeto de estudo. Neste caso, a pesquisa será descritiva, pois fará um panorama dos dados coletados por meio de questionário.

Para que as informações fossem coletadas, empregou-se a técnica de pesquisa levantamento (survey). Gil (2019) a descreve como uma arguição direta às pessoas sobre algo que deseja ser conhecido. A objetividade é um ponto forte deste tipo de técnica, além dos baixos custos da aplicação de um questionário. Outra vantagem é a facilidade de quantificar as informações coletadas repetidamente em diversos questionários, possibilita compreender padrões nas respostas que vão permitir diagnosticar o problema proposto.

Por se tratar de um método rápido e direto, o levantamento pode ser raso em sua análise por não se aprofundar em outras questões não contempladas no questionário ou omitidas por quem responde, ou ainda, incapaz de verificar perspectivas futuras, tendências, visto que só é possível registrar o estado atual do entrevistado e isso limita o poder de mudança que pode ser empregado (GIL, 2019).

Um questionário sobre aspectos no trabalho se torna mais útil para uma pesquisa descritiva, que busca descrever a situação atual dos trabalhadores, quantificar sua percepção e posicionamento sobre a condição de trabalho.

O modelo de questionário utilizado foi a escala de Qualidade de Vida no Trabalho (EQVT), validada por Timossi et al. (2008). Trata-se de uma formatação à luz das características relevantes à satisfação no trabalho, utilizando perguntas objetivas, a cada pergunta o entrevistado deve atribuir sua avaliação por meio de uma escala de intensidade ordinal, que varia de 1 como "muito insatisfeito" a 5 que representa "muito satisfeito".

Além da EQVT, o suporte que os trabalhadores possuem foi verificado por meio da Escala de Percepção de Suporte Organizacional (EPSO) validada por Siqueira e Gomide Jr. (2008). Estes autores esclarecem que a teoria utilizada para elaboração e validação da escala 
foi inicialmente desenvolvida por Eisenberger et al. (1986) que contêm questões referentes ao suporte no trabalho dado pelas organizações.

A amostra da pesquisa foi constituída por 16 trabalhadores de seis empresas de correspondentes bancários terceirizados, localizadas no município de Corumbá-MS. Os trabalhadores foram selecionados por conveniência. Gil (2019) ressalta que é um método de seleção de uma amostra pela sua disponibilidade, possui o benefício de praticidade, porém não existe nenhuma garantia de que essa amostra represente a população.

Os dados foram coletados no período de agosto a outubro de 2019.

Os dados foram analisados por estatística descritiva, utilizando a amostra da população, o que permite tirar conclusões que podem ser válidas ou não a toda a população, desde que estabelecidos os procedimentos necessários, tanto na coleta de dados, quanto no planejamento do trabalho e por fim na análise e descrição das informações (SANTOS, 2007). Neste caso, não houve generalização devido ao tipo de amostragem utilizada.

Dentre os procedimentos de estatística para análise dos dados, foi utilizada a média que conforme detalha Vieira (2018) apresenta a tendência central das observações coletadas de uma variável. Será utilizado também o desvio padrão, sendo ele a raiz quadrada da variância que representa o quanto podem ir longe os valores observados do valor esperado.

Para verificar a relação entre as variáveis Qualidade de Vida no Trabalho e Suporte no Trabalho foi utilizado teste de correlação bivariada coeficiente de correlação de Pearson (p de Pearson), adequado para amostras independentes (LIRA, 2004).

De acordo com Mukaka (2012), os resultados podem ser interpretados da seguinte forma: 0,9 correlação muito forte; 0,7 a 0,9 correlação forte; 0,5 a 0,7 correlação moderada; 0,3 a 0,5 correlação fraca; e 0 a 0,3 correlação desprezível. Estes resultados podem ser utilizados mesmo quando a correlação é positiva ou negativa (correlação inversa).

A próxima seção abordará aspectos relevantes sobre o objeto de pesquisa, proporcionando esclarecimentos sobre as instituições de crédito e os participantes da pesquisa.

\section{RESULTADOS E DISCUSSÕES}

\subsection{Contextualização da organização e do setor de correspondentes bancários}

O mercado de crédito à pessoa física no Brasil pode ser caracterizado, como trata Sobrinho (2003), centralizado e monopolizado pelo fato de o mercado bancário ser controlado 
por poucos bancos múltiplos, porém sua forma de contratação é pulverizada com diversos agentes de crédito operando.

Após a lei de terceirização, houve a flexibilização para contratação de empresas prestadoras de serviços, se antes podiam prestar serviços apenas em atividade meio, como segurança e limpeza, agora atividades fins, isto é, aquelas que geram o lucro ao banco, podem ser incluídas sem prejuízo jurídico ao banco (SANTOS, 2017).

Esse movimento de terceirização dos serviços ocorria antes mesmo de a lei ser aprovada e respaldou a terceirização do setor bancário, fato comprovado no estudo de Loureiro, Madeira e Bader (2016) em que foi levantado que de 20.000 correspondentes existentes no país em 2000 saltou para mais 150.000 até 2010.

Um correspondente bancário de crédito trabalha com a oferta direta ao cliente de soluções financeiras, que vão desde a crédito direto ao consumidor (CDC), que engloba empréstimos de curto prazo (hot money), consignado (empréstimo cuja parcelas são preferencialmente cobradas direta na folha de pagamento do cliente via de convênio da empresa pagadora com o banco), além de antecipações de $13^{\circ}$ salário e antecipação de restituição de imposto de renda. Os financiamentos habitacionais e crédito rural podem também passar pelos correspondentes. A prospecção de clientes e a coleta de documentos dinamizam e geram menores custos de processo para o banco (LOUREIRO; MADEIRA; BADER, 2016).

A receita que advém aos correspondentes chega por meio de comissão pelas atividades realizadas (DINIZ, 2010). Este fato torna o mercado muito competitivo, com muitos correspondentes e muita oferta de crédito, essa oferta pode ocorrer de três formas:

1. Telemarketing: contatos telefônicos à lista de clientes, além de mensagens por celular.

2. Atendimento de Balcão: clientes que comparecem ao espaço físico do correspondente.

3. Visita: funcionários que se deslocam até empresas, órgãos públicos ou eventos onde esteja presente o público-alvo para oferta de crédito.

Esta versatilidade de formas de ofertas aos clientes representa uma vantagem competitiva para o negócio (DINIZ, 2010), porém ao trabalhador pode significar grandes riscos à sua satisfação no trabalho.

Além da exposição a diversas doenças físicas como lesões causadas pela falta de ergonomia, LER entre outras, há ainda a pressão psicológica pela venda, pois assim como a empresa, o salário do funcionário depende de comissão, a insalubridade de ambientes onde 
não há um padrão exigido de uma agência bancária, o esgotamento mental e físico de uma atividade em que a competitividade alta e o suporte de trabalho tende a ser precário.

Como exemplo, uma das organizações participantes está instalada em Corumbá-MS há 11 anos e se trata de uma das pioneiras como correspondente bancário na cidade. Fundada na capital Campo Grande, a empresa estabeleceu várias filiais pelo Estado, e chegou a ter 7 funcionários atuando em Corumbá-MS.

A empresa sempre estabeleceu duas formas básicas de atendimento, a primeira o atendimento de balcão a quem entra na loja, sempre se localizando em praças estratégicas como regiões movimentadas e próximas a bancos. Mas o ponto forte da empresa é a segunda, o telemarketing, com oferta direta ao cliente por meio de ligações telefônicas e mensagens de celular.

Com uma estrutura que se assemelha a uma sala de telemarketing, seus funcionários trabalham a maior parte do tempo realizando ligações aos clientes de suas listas que são organizadas em software próprio de cadastramento de clientes. Este software torna possível distribuir os clientes aos atendentes para que cada um possua uma carteira de clientes a ser contatados e fidelizados.

Com as transformações digitais e mudanças impostas pelo mercado, a empresa foi vendida a um grupo de sócios e hoje atua com quatro funcionários com foco nas contratações de crédito por meio de atendimento de balcão, visitas para prospecção em órgãos públicos e escolas, e pela indicação de clientes com bom relacionamento.

Jayo e Diniz (2010) abordam que os clientes que buscam um correspondente bancário ao invés de se dirigir a uma agência, buscam primeiro a praticidade no atendimento, sem filas ou burocracia para adentrar ao estabelecimento, também há um relacionamento negocial criado com os funcionários da empresa, devido à oferta ativa das ligações e atendimento que busca a diferenciação para conquistar e fidelizar o cliente.

\subsection{Análise dos dados}

A partir dos dados coletados, foi possível realizar aferições dos questionários respondidos pelos colaboradores dos correspondentes bancários e empresas de crédito e realizar a análise com base na teoria de QVT. Foram entrevistados 16 colaboradores de seis instituições de crédito, todos localizados em Corumbá-MS.

O questionário aplicado aos entrevistados versou sobre os aspectos da QVT à luz do modelo de Walton (1973) no formato de respostas, utilizado pela organização mundial da 
saúde que padroniza as respostas aos questionamentos e facilita a análise por meio da escala tipo Likert de 5 pontos, tendo 1 como "muito insatisfeito" a 5 "muito satisfeito" (FLECK, 2000).

Os resultados dos fatores de qualidade de vida no trabalho e suporte no trabalho estão dispostos na Tabela 1 .

Tabela 1 - Resultados dos Fatores de Qualidade de Vida no Trabalho e Suporte no Trabalho

\begin{tabular}{|c|c|c|c|c|c|}
\hline Constructo & Fatores & \multirow{2}{*}{$\begin{array}{c}\text { Média } \\
3,84\end{array}$} & \multirow{2}{*}{$\begin{array}{l}\text { DP } \\
0,52\end{array}$} & \multicolumn{2}{|c|}{$\begin{array}{l}\text { Mínim Máximo } \\
\text { o }\end{array}$} \\
\hline \multirow{8}{*}{$\begin{array}{l}\text { Qualidade de vida } \\
\text { no trabalho }\end{array}$} & Importância do trabalho & & & 3,00 & 4,80 \\
\hline & Condições de trabalho & 3,75 & 0,53 & 2,67 & 4,83 \\
\hline & Espaço que o trabalho ocupa em sua vida & 3,52 & 0,47 & 2,33 & 4,33 \\
\hline & Respeito às Leis & 3,44 & 0,51 & 2,50 & 4,25 \\
\hline & Integração social & 3,44 & 0,61 & 2,50 & 4,50 \\
\hline & Capacidades no trabalho & 3,44 & 0,85 & 1,80 & 4,80 \\
\hline & Salário (compensação) justo e adequado & 3,27 & 0,84 & 2,00 & 5,00 \\
\hline & Oportunidades no trabalho & 3,13 & 0,86 & 1,75 & 4,50 \\
\hline & Suporte social informacional & 2,79 & 0,69 & 1,71 & 3,86 \\
\hline \multirow{2}{*}{\multicolumn{2}{|c|}{ Suporte no Trabalho Suporte social instrumental }} & 2,70 & 0,63 & 1,60 & 3,80 \\
\hline & Suporte social emocional & 2,33 & 0,58 & 1,50 & 3,50 \\
\hline
\end{tabular}

Fonte: Dados da pesquisa (2019).

A Tabela 1 apresenta os resultados sobre a qualidade de vida no trabalho e suporte no trabalho. Os conceitos utilizados foram estabelecidos por Walton (1973), tendo oito indicadores que buscam aspectos internos e externos que afetam a qualidade de vida do trabalhador. A percepção de suporte no trabalho foi estabelecida por Siqueira e Gomide Jr. (2008) em três fatores sociais relevantes: informação, instrumentos e emocional.

Percebe-se que todos os indicadores que tratam da QVT apresentaram média geral superior a 3 e inferior a 4, portanto os fatores: Importância do trabalho, Condições de trabalho e Espaço que o trabalho ocupa em sua vida, foram avaliados como neutros com tendência a satisfatório e os fatores Respeito às Leis, Integração social, Capacidades no trabalho, Salário (compensação) justo e adequado, Oportunidades no trabalho, como itens de neutralidade para insatisfatório.

O aspecto "Importância do Trabalho", fator com maior média $(3,84)$, aborda o orgulho de trabalhar na empresa e de vender seus produtos e responsabilidade social da empresa, apresenta uma neutralidade com índice satisfatório, isso reflete que, embora seja um serviço terceirizado, os correspondentes realizam serviços bancários iguais aos da instituição financeira que terceirizou o serviço e seus funcionários reconhecem essa importância, porém de forma moderada. 
Outros dois aspectos que apresentaram neutralidade satisfatória são as condições de trabalho (média=3,75), que aborda a segurança, salubridade e a jornada de trabalho (WALTON, 1973); e espaço que o trabalho ocupa em sua vida (média=3,72), tratando da relação entre aspectos da vida particular como lazer, descanso, local e horário e trabalho (WALTON, 1973), tendo resultados neutros com tendências a satisfatório.

Os demais itens apresentam média neutra com viés de insatisfação o que representa que aspectos como respeito às leis, salário e oportunidades de crescimento possuem uma certa insatisfação, pois como trata Santos (2017), a terceirização representa a liberdade dos bancos de delegar serviços bancários a salários bem menores, com menos direitos e sem necessidade de proposição de plano de carreira ao trabalhador, reduzindo custos e responsabilidades.

Ainda em observação aos valores mínimos, máximos e dispersão da Tabela 1, destacase o elevado desvio padrão dos itens: capacidade, oportunidades e salários, acima de 0,8, portanto com respostas menos homogêneas, apresentando uma certa divergência nas respostas. O desvio padrão demonstra que, embora a média apresente uma tendência central, existe diversidade na percepção do fenômeno em que muitas ideias não convergem para respostas semelhantes (DALFOVO; LANA; SILVEIRA, 2019).

A Tabela 1 mostra ainda a análise do suporte do trabalho. Apresenta resultados diferentes da QVT apresentando avaliações com médias abaixo de 3 e desvio padrão não superior 0,7 . Neste caso, os resultados tendem a ser considerados como muito insatisfeito a satisfeito, este resultado demonstra que os trabalhadores podem estar se sentindo desamparados pelas empresas terceirizadas nos três fatores do suporte de trabalho.

Como aponta Siqueira e Padovan (2008), o suporte emocional se sobrepõe aos dois outros aspectos no suporte do trabalho em termos de importância. Os resultados demonstram que o fator emocional possui a menor média $(2,33)$ dos três itens, com o menor desvio padrão $(0,57)$, ou seja, as respostas possuem um nível maior de homogeneidade, portanto refletem que de fato há um certo consenso sobre o suporte emocional aos trabalhadores.

Siqueira e Padovan (2008) investigam as causas dessa insatisfação em termos emocionais e apontam que os principais motivos passam pelas atitudes do gestor direto. Muitas vezes, estes desconhecem as competências dos colaboradores, os pontos a serem melhorados, os treinamentos que podem ser realizados, atuam sem experiência e conhecimento sobre gestão e liderança, entregam pouca força motivacional, se acomodam, dentre outros. 
Este resultado corrobora as informações do Anuário do Sistema Público de Emprego, Trabalho e Renda, para o qual as doenças psicológicas como depressão e ansiedade cresceram mais de 25\% em 2016 (DIEESE, 2017).

Em termos de suporte informacional e instrumental, os resultados mostraram que as organizações atendem de forma neutra a satisfatória, obtendo média de 2,79 para o primeiro e 2,70 para o segundo. De acordo com Siqueira e Padovan (2008), este tipo de suporte permite que os colaboradores recebam informações e estrutura adequadas para realização de suas atividades.

A próxima análise apresenta os resultados do teste da hipótese formulada, disposta na Tabela 2.

Tabela 2 - Correlação entre os constructos Qualidade de Vida no Trabalho e Suporte no Trabalho

\begin{tabular}{clcc}
\hline \multicolumn{1}{c}{ Constructos } & \multicolumn{1}{c}{ Testes } & $\begin{array}{c}\text { Qualidade de vida no } \\
\text { trabalho }\end{array}$ & $\begin{array}{c}\text { Suporte no } \\
\text { Trabalho }\end{array}$ \\
\hline \multirow{2}{*}{$\begin{array}{c}\text { Qualidade de vida no } \\
\text { trabalho }\end{array}$} & Correlação de Pearson & 1,00 & 0,75 \\
& Significância & - & 0,001 \\
& N amostral & 16 & 16 \\
Suporte no Trabalho & Correlação de Pearson & 0,75 & 1,00 \\
& Significância & 0,001 & - \\
& N amostral & 16 & 16 \\
\hline Fonte: Dados da pesquisa (2019).
\end{tabular}

Fonte: Dados da pesquisa (2019).

A Tabela 2 apresenta o resultado do teste de correlação de Pearson e seu nível de significância. Este teste calcula o coeficiente de correlação entre duas variáveis quantitativas, os resultados variam de -1 a 1 , no qual quanto mais próximo de 1 significa que as variáveis seguem no mesmo sentido e quando mais distante, o oposto (SANTOS, 2007). Para esta pesquisa, demonstra o quanto o suporte no trabalho se alinha a qualidade de vida no trabalho baseado nos dados coletados junto aos trabalhadores.

A relação de influência do suporte do trabalho foi de $75 \%$ no discernimento sobre a qualidade de vida do trabalho, então conforme os parâmetros estabelecidos, os resultados foram significantes e mostram uma relação forte de influência do trabalho na QVT dos trabalhadores dos correspondentes de crédito, portanto pode-se inferir que existe uma alta correlação positiva entre suporte de trabalho e QVT.

Diante dos resultados, considera-se o que aponta Siqueira e Padovan (2008), corroborando com os resultados das estatísticas descritivas aqui apresentados, que somente as 
práticas de QVT sem o devido suporte ao trabalho podem ser insuficientes para gerar satisfação ao trabalhador.

Esta afirmação de Siqueira e Padovan (2008) é fundamentada em suas observações de que as empresas investem muito em políticas de melhoria do espaço, da ergonomia, nas ferramentas ao trabalhador, porém quando se trata de suporte, há uma ausência de empatia, carinho, confiança, estima e escuta do que o trabalhador tem a dizer, estes aspectos se sobrepõem e levam a avaliação de QVT para níveis ruins, acrescidos de insatisfação, em termos de suporte de trabalho.

\section{CONSIDERAÇÕES FINAIS}

O presente trabalho buscou interpretar como os funcionários dos correspondentes bancários de Corumbá-MS percebem sua qualidade de vida no trabalho e o suporte recebido por eles na organização em que atuam. Após a aprovação da lei de terceirização, que retirou os limites de contratação de terceirizados para área fim e área meio, este setor pode em alguns anos se tornar o que vai preponderar no atendimento físico aos clientes dos bancos em detrimento do atendimento tradicional em agências bancárias.

O problema proposto foi conhecer como estes trabalhadores se sentem sobre os fatores de QVT de Walton (1973) e qual o nível de suporte no trabalho percebe, com o objetivo de avaliar um grupo de trabalhadores na cidade por meio do questionário sobre satisfação no trabalho, verificando de forma quantitativa suas respostas e se haveria uma correção entre suporte do trabalho e percepção de QVT dos empregados.

Após análise estatística dos resultados, foi possível perceber que existe um nível de QVT de neutro para satisfeito e de neutro para insatisfeito dos funcionários, demonstrando no geral de neutralidade sobre as políticas de QVT praticadas pelas suas empresas, notas acima de 3 e inferior a 4, um nível de indiferença e passividade sobre este tema. Foi possível perceber que as impressões sobre políticas de QVT apresentaram desvio padrão maior que o de suporte no trabalho com respostas máximas e mínimas mais extremas, o que demonstra que existe homogeneidade baixa nas respostas.

O dados sobre suporte no trabalho apresentaram resultados de insatisfação e muita insatisfação, com um desvio padrão baixo demonstrando homogeneidade nas respostas e uma coesão na percepção de que há um déficit de suporte do empregador aos seus funcionários em todos os três aspectos elencados. 
O suporte emocional, além de ser o item mais relevante, apresentou a menor nota de todas com o menor desvio padrão e reflete o descuido que há com a parte emocional do trabalhador terceirizado.

Pelo coeficiente de Pearson foi possível demonstrar uma alta correlação positiva de $75 \%$ entre o suporte de trabalho e a QVT, com significância de 0,01\%.

Sobretudo a falta de apoio emocional pode gerar doenças psicológicas graves aos trabalhadores. Mais do que falta de práticas de QVT é a falta de estrutura emocional que as empresas podem omitir, deixando o trabalhador em situação de desamparo refletida em seus níveis de satisfação com o trabalho.

Portanto pode-se concluir que o objetivo de avaliar os trabalhadores sobre sua satisfação e suporte no trabalho foi concluído, com resultados tanto no sentido de práticas de QVT em todos os aspectos relevantes do modelo de Walton (1973), com neutralidade em relação a suas políticas. Quanto ao suporte no trabalho, conclui-se que há um nível de insatisfação homogêneo dentre os empregados, uma ausência de suporte social e sobretudo de suporte emocional ao trabalhador, fato que o deixa exposto a doenças físicas e psicológicas.

Em termos de contribuição, esta pesquisa permite ações gerenciais, sendo que as organizações pesquisadas podem se apropriar destas informações para elaborarem planos de ação para melhoria nos aspectos aqui avaliados.

Como trabalho futuro, sugere-se uma análise sobre o comportamento dos líderes nestas organizações, visto que, conforme apontado pela literatura, estes têm influência significativa no suporte emocional dos trabalhadores.

\section{REFERÊNCIAS}

ALVAREZ, B. R. Estilo de vida e hábitos de lazer de trabalhadores, após dois anos de aplicação de um programa de ginástica laboral e saúde: caso - Intelbras. 2002. 185 f. Tese (Doutorado em Engenharia de Produção, Área de Concentração: Ergonomia) - Universidade Federal de Santa Catarina, Florianópolis, 2002.

ALVES, C. R. A; CORREIA, A. M. M; SILVA, A. M. Qualidade de vida no trabalho (QVT): um estudo em uma instituição federal de ensino superior. Revista Gestão Universitária na América Latina-GUAL, Florianópolis, p. 205-227, jan., 2019. Disponível em: https://doi.org/10.5007/1983-4535.2019v12n1p205. Acesso em: 30 abr. 2020.

BORGES, C. L. P.; VAlle C. C.; FABRICIO J. C. Políticas de Qualidade de Vida no Trabalho em uma Instituição Particular de Ensino Fundamental e Médio em Laranjeiras do Sul - PR. Rio de Janeiro: CNEG \& Inovarse, 2015. Disponível em <www.admpg.com.br/2015/down.php?id=1805\&q=1>Acesso em 10 de maio de 2019. 
CARNEIRO, D. D. A.; LÉDO, B. M. C. A importância da Qualidade de Vida dos funcionários responsáveis pelo controle de estoque no programa de Qualidade Total de uma empresa. Brazilian Journal of Development, Curitiba, v. 5, n. 11, p.26557-26569 nov., 2019. Disponível em: https://doi.org/10.34117/bjdv5n11-286. Acesso em: 30 abr. 2020.

COBB, S. Social support as a moderator of life stress. Psychosomatic Medicine, v. 38, n. 5, p. 300-314, 1976. Disponível em https://doi.org/10.1097/00006842-197609000-00003, acessado em 4 de maio de 2020.

DALFOVO, M. S.; LANA, R. A.; SILVEIRA, A. Métodos quantitativos e qualitativos: um resgate teórico. Revista Interdisciplinar Científica Aplicada, Blumenau, v.2, n.4. 2008.

DESSEN, M. C.; PAZ, M. G. T. Bem-estar pessoal nas organizações: o impacto de configurações de poder e características de personalidade. Psicologia: Teoria e Pesquisa, v. 26, n. 3, p. 549-556., 2010. Disponível em: 〈http://www.scielo.br/pdf/ptp/v26n3/a18v26n3>, acesso em: 10 de maio de 2019.

DIEESE, ANUÁRIO do Sistema Público de Emprego, Trabalho e Renda 2016: Indicadores da Saúde do Trabalhador com base na Rais: livro 7. São Paulo: Departamento Intersindical de Estatística e Estudos Socioeconômicos, 2017. Disponível em: <https://www.dieese.org.br/anuario/2017/Livro7_Saude.pdf>, acesso em 11 de maio de 2019.

DINIZ, E. H. Correspondentes Bancários e Microcrédito no Brasil: Tecnologia Bancária e Ampliação dos Serviços Financeiros para a População de Baixa Renda. Rio de Janeiro: FGV, 2010. Disponível em:< https://bibliotecadigital.fgv.br/dspace/handle/10438/13365>, acesso em 10 de maio de 2019

EISENBERGER, R.; HUNTINGTON, R.; HUTCHISON, S.; SOWA, D. Perceived organizational support. Journal of Applied Psychology, v. 71, n. 3, p. 500-507, 1986. Disponível https://doi.org/10.1037/0021-9010.71.3.500, acessado em 4 de maio de 2020.

FERNANDES, E. Qualidade de vida no trabalho: como medir para melhorar. Salvador: Casa da Qualidade, 1996.

FLECK, M. P. D. A. O instrumento de avaliação da qualidade de vida da OMC WHOQOL100: Caraterísticas e perspectivas. Revista cienc. saúde coletiva, v. 5, n. 1, Rio de Janeiro, 2000. Disponível em https://www.scielo.br/pdf/csc/v5n1/7077.pdf, acesso em 20 de novembro de 2019.

HAMMER, L. B.; ZIMMERMAN, K. L. Quality of work life. 2011.

GIL, A. C. Métodos e Técnicas de Pesquisa Social. 7 ed. São Paulo: Atlas, 2019.

GRÜNSPAN, M. Qualidade de vida no trabalho em escritórios de contabilidade de Santa Maria/RS. Revista Eletrônica de Contabilidade. Santa Maria/RS, v.1, n.2, p. 148-163, dez. 2004 a fev. 2005.

HANDY, C. A era do paradoxo: Dando um sentido para o futuro. São Paulo: Makron Books, 1995. 
HOUSE, J. S. Work stress and social support. Reading, MA: Addison Wesley, 1981.

JAYO, M.; DINIZ, F. H. Uso de Correspondentes Bancários pelos Bancos Brasileiros: Um Mapeamento dos Modelos de Gestão de Redes. Encontro da ANPAD, 34, 2010, Rio de Janeiro. Anais... Rio de Janeiro: ANPAD, 2010. Disponível em http://www.anpad.org.br/diversos/down_zips/53/adi1272.pdf, acesso em 9 de maio de 2020.

KEYNES, Jhon Maynard. Teoria Geral do Juro do Emprego e da Moeda. São Paulo: Saraiva, 2014.

LIRA, S. A. Análise de Correlação: abordagem teórica e de construção dos coeficientes com aplicações. 2004. 112 f. Dissertação (Mestrado em Ciências - Métodos Numéricos em Engenharia dos Setores de Ciências Exatas e de Tecnologia) - Universidade Federal do Paraná, Curitiba, 2004.

LÍRIO, A. B.; SEVERO, E. A.; GUIMARAES J. C. F. A Influência da Qualidade de Vida no Trabalho Sobre o Comprometimento Organizacional. Revista Gestão \& Planejamento, Salvador, v. 19, jan./dez., 2018.

LOUREIRO, E. R.; MADEIRA, G. A.; BADER, F. L. C. Expansão dos Correspondentes Bancários no Brasil: uma análise empírica. Brasília, BACEN, 2016. Disponível em <https://www.bcb.gov.br/pec/wps/port/wps433.pdf>Acesso em 11 de maio de 2019.

MILHOME, J. C.; ROWE, D. E. O.; SANTOS, M. G. D. Existem Relações entre Qualidade de Vida no Trabalho, Comprometimento Organizacional e Entrincheiramento Organizacional?. Contextus - Revista Contemporânea de Economia e Gestão, v. 16, n. 3, p. 232-252, 2018.

MUKAKA, M. M. A guide to appropriate use of Correlation coefficient in medical research. Malawi Medical Journal, v. 24, n. 3, p. 69-71, 2012.

OLIVEIRA, S. L. Tratado de Metodologia Cientifica. 2 ed., São Paulo: Editora pioneira. 1997.

REIS, Pedro Ferreira et. al. O uso da flexibilidade no programa de ginástica laboral compensatória, na melhoria da lombalgia em trabalhadores que executam suas atividades sentados. In: Congresso Internacional de Educação Física - FIEP. Anais... São Paulo, 2003.

SANTOS, C. Estatística descritiva: manual de auto-aprendizagem. Lisboa: Edições Silabo, 2007.

SANTOS, E. R. A Nova Lei da Terceirização - Lei n. 13.429/2017:Um cheque em branco ao empresariado. Revista do TRT da 5. Região, n. 51, p. 69-78, jul./dez., 2017. Disponível em: <https://juslaboris.tst.jus.br/bitstream/handle/20.500.12178/125417/2017_santos_enoque_nov a_lei.pdf?sequence=1\&isAllowed=y>, acesso em 11 de maio de 2019.

SILVA, J.; TARANTO, I. C.; PIASECKI, F. Ginástica laboral: alongamento x flexionamento. SaBios-Revista de Saúde e Biologia. Campo Mourão, v. 1, n. 2, p. 6-12, 2006. 
SIQUEIRA M. M. M.; GOMIDE JR., S. Suporte no Trabalho. In.: SIQUEIRA, M. M. M. (org). Medidas de comportamento Organizacional, São Paulo. Artmed, 2008, p. 283-294.

SIQUEIRA, M. M. M.; PADOVAM, V. A. R. Bases teóricas de bem-estar subjetivo, bemestar psicológico e bem-estar no trabalho. Psic.: Teor. e Pesq., Brasília, v. 24, n. 2, p. 201209, junho, 2008. Disponível em: 〈http://www.scielo.br/pdf/ptp/v24n2/09>, acesso em $10 \mathrm{de}$ maio de 2019.

TIMOSSI, L. S.; PEDROSO, B.; PLATTI, L. A. FRANCISCO, A. C. Adaptação do modelo de Walton para avaliação da Qualidade de Vida no Trabalho. Journal of Physical Education, v. 20, n. 3, p. 395-405, outubro, 2009. Disponível em http://www.periodicos.uem.br/ojs/index.php/RevEducFis/article/view/5780, acesso em $10 \mathrm{de}$ maio de 2019.

VASCONCELOS, A. F. Qualidade de vida no trabalho: origem, evolução e perspectivas. Cadernos de Pesquisas em Administração, São Paulo, v. 8, n. 1 jan/mar, 2001.

VIEIRA, Sonia. Estatística básica. 2 ed. São Paulo: Cengage Learning Editores, 2018.

WALTON, R. E. Quality of working life: what is it? Slow Management Review, Cambridge, v. 15, n. 1, p. 11-21, 1973.

\section{Como Referenciar este Artigo, conforme ABNT:}

THIAGO, F; ARAÚJO, T. C. C; GONÇALVES, C; MARCIEL, W. R. E. Qualidade de Vida no Trabalho e Suporte no Trabalho Terceirizado de Organizações de Crédito. Rev. FSA, Teresina, v.18, n. 02 , art. 1, p. 3-23, fev. 2021.

\begin{tabular}{|l|c|c|c|c|}
\hline \multicolumn{1}{|c|}{ Contribuição dos Autores } & F. Thiago & $\begin{array}{c}\text { T. C. C. } \\
\text { Araújo }\end{array}$ & $\begin{array}{c}\text { C. } \\
\text { Gonçalves }\end{array}$ & $\begin{array}{c}\text { W. R. E. } \\
\text { Marciel }\end{array}$ \\
\hline 1) concepção e planejamento. & $\mathrm{X}$ & $\mathrm{X}$ & & \\
\hline 2) análise e interpretação dos dados. & $\mathrm{X}$ & $\mathrm{X}$ & & \\
\hline 3) elaboração do rascunho ou na revisão crítica do conteúdo. & $\mathrm{X}$ & $\mathrm{X}$ & $\mathrm{X}$ & $\mathrm{X}$ \\
\hline 4) participação na aprovação da versão final do manuscrito. & $\mathrm{X}$ & $\mathrm{X}$ & $\mathrm{X}$ & $\mathrm{X}$ \\
\hline
\end{tabular}

